\title{
To Restudy of Fundamental Problems Imperative
}

\author{
Tokusaburo KosAKA*
}

Thirteen years have elapsed since the termination of World War II. Japan's industrial production, its expansion and reinforcement of production facilities and equipment have been swiftly accelerated thanks to the Government's policies of fostering the country's industries as well as the industries' own efforts in rationalizing management based on scientific methods. As a result, the modernization of equipment and facilities in various industries of the country has been carried out and accomplished with extraordinary success. The development of Japan's electrochemical industry, too, has witnessed a progress second to none compared with other industries.

This rapid and extraordinary development of the electrochemical industry had never been dreamed of a few decades ago. It is indeed a matter of felicitation both for the electrochemical industry as well as the nation. We must also express profound gratitude and respect for the many leaders as well as the engineers in the industry, who have, with their untiring effort and self-sacrifice, made such an extraordinary development possible.

The carbide, fertilizer, soda and ferro-alloy industries have all recovered to such an extent today that they simply cannot be compared with the same industries in the past. Technology has reached a world-wide level and production capacity has also exceeded by far, that of prewar days.

However, we must admit that there are still great number of problems involved in the electrochemical industry today. In addition to the ever revolving phenomenon of increase in supply and decline in demand in Japan's postwar economy particularly based on the phenomenal developments of technology, there is the fierce international competition in which Japanese export goods must find a way to surmount. These problems confronting the Japanese electrochemical industry cannot be eliminated in a year or two. This is where the destiny of our country's electrochemical industry lies.

Considerable developments have also been witnessed recently in the field of the petrochemical and gas chemical industries thanks to the acquirement of sufficient equipment funds as well as the Government's positive measures in strongly fostering these industries by the application of various tax exemption measures, etc. The products of these two industries are proving to be raw materials for the chemical industry, and these products are oppressing the electrochemical products, especially the carbide derived products, in the greater part of industry.

The history of the electrochemical industry is an old one. The history of the ferro-alloy industry dates back to 40 years, that of the carbide industry 50 years and the history of the soda industry can be traced back to 70 years. However, in the world of chemical industry, the old history alone is not the factor of development and progress.

Phenomenal developments and progress have been witnessed recently in the field of industrial technology. The speed of fundamental and applied researches as well as the tempo of industrialization has been cut down drastically, and the results of all these researches have borne fruits in the revolution created in the field of industrial technology. The works done in the field of research has directly braught new international commodities and have advanced into the world's markets. Very sort of investment activities in researches creates industrial technology in the forms of new commodities and capital. These research investments, together with equipment investments, have already become important factors in deciding the direction and speed of industrial development.

Let us now ask ourselves a question concerning whether such progressive factors are being fostered

\footnotetext{
* President, Shin-etsu Chemical Industry Co., Ltd.
} 
today by Japan's electrochemical industry itself. Looking from this viewpoint, I believe that Japan's electrochemical industry is now at a stage of a big ordeal, after thirteen years of tremendous postwar development.

On our country's electrochemical industry, it is said that the problems can all be pinpointed to the supply of electric power and raw material. Here, then, is the fundamental problem facing Japan's electrochemical industry.

In regard to the electric power problem, particularly in the case of the electrochemical industry, the hitherto cheap supply of power no longer holds true today. Although it is true that the development of power sources has witnessed tremendous and rapid growth after surmounting various financial and technological difficulties today, the stage has now arrived when much cannot be relied upon hydroelectric power to obtain the absolute amount of energy necessary for the electrochemical industry. Whether it be imported fuels or domestically produced coal, the time has now arrived when we must do something about measures in cutting down on the energy consumption ratio as well as strive to put atomic energy production on a commercial price as immediately as possible.

Even concerning the problem of coke as a raw material, although imported coal is an exception, in the case of domestically produced coke, the various gas enterprises have already reached a limit. Therefore, the fundamental problems now facing gas enterprises are to switch over from the present dry distillation to the complete gasification of coal as the use of oil gas producer. Because of the fact that the gas enterprises are public enterprises and a low price policy is being taken politically, the price of coke is tremendously affected by this policy.

Various problems also are involved in the ferroalloy industry in regard to the importation of ores as well as export of the products. The import of raw material salt in the soda industry also poses a big problem.

After one year of difficulties, the shallow-bottomed Japanese economy is said to be crawling on the bottom of a pot at present. What I would like to advise to the staff of management as well as engineers at this opportunity, in the midst of revolutionary changes in technology as well as the fierce international competition, is that in ordet to prepare for the future development of the electrochemical industry of Japan, further efforts must be taken to restudy such fundamental problems as those concerning technology and raw material, etc.

(Received July 11, 1958) 